\title{
Characterization of the response of spring-based relative gravimeters during paroxysmal eruptions at Etna volcano
}

\author{
Filippo Greco ${ }^{1 *}$, Valerio lafolla ${ }^{2,3}$, Antonio Pistorio ${ }^{1,4}$, Emiliano Fiorenza ${ }^{2,3}$, Gilda Currenti ${ }^{1}$, Rosalba Napoli ${ }^{1}$, \\ Alessandro Bonaccorso ${ }^{1}$ and Ciro Del Negro ${ }^{1}$
}

\begin{abstract}
Gravity time sequences collected at Etna volcano by continuously recording spring-based relative gravimeters showed significant variations in temporal correspondence with paroxysmal eruptions. Since the observed gravity variations can only be partially related to subsurface mass redistribution phenomena, we investigated the instrumental effects due to ground vibrations such as those that accompany explosive activity. We simulated the performances of relative gravimeters with laboratory experiments to estimate their response to vertical and horizontal excitations. Laboratory tests were carried out using a vibrating platform capable of accelerating the instruments with intensities and frequencies, in both the vertical and horizontal directions, observed in the ground vibrations associated with paroxysmal events. The seismic signals recorded at Etna volcano during the 10 April 2011 lava fountain were analyzed to retrieve the parameters used to drive the vibration platform. We tested two gravimeters used for Etna volcano monitoring: the LaCoste \& Romberg D\#185 (Lafayette, CO, USA) and the Scintrex CG-3 M\#9310234 (Concord, ON, Canada). The experiment results highlight that the vibrations resembling the seismic waves propagated during paroxysmal events cause an amplitude response in the gravity readings on the order of several hundred microgals $(\mu \mathrm{Gal})$. Generally, the relationship between the vibrations and the gravimeter response is nonlinear, with a fairly complex dependence on the frequencies and amplitudes of the signals acting on the gravimeters.
\end{abstract}

Keywords: Spring-based relative gravimeter; Vibrating platform; Volcano monitoring; Explosive eruptions; Gravity changes

\section{Background}

Gravity measurements are a powerful method to investigate mass and density changes, which are useful in many branches of earth science. In particular, repeated gravity surveys conducted at active volcanoes have proved to be effective for monitoring purposes, since they are able to detect subsurface magma movements before volcanic unrest (Williams-Jones and Rymer 2002; Battaglia et al. 2003; Furuya et al. 2003; Carbone and Greco 2007; Bonaccorso et al. 2011a; Greco et al. 2010, 2012; Del Negro et al. 2013). Gravity monitoring of volcanic areas is traditionally performed by means of time-lapse surveys, allowing the detection of temporal gravity changes

\footnotetext{
*Correspondence: filippo.greco@ct.ingv.it

${ }^{1}$ Istituto Nazionale di Geofisica e Vulcanologia, Sezione di Catania,

Osservatorio Etneo, Piazza Roma 2, Catania 95125, Italy

Full list of author information is available at the end of the article
}

over relatively long periods (from months to years; e.g., Berrino 2000; Carbone et al. 2003a; Bonaccorso et al. 2011a; Greco et al. 2010, 2012; Pistorio et al. 2011; Del Negro et al. 2013). Continuous gravity measurements at volcanic sites are rarely performed (Berrino et al. 1997, 2006; Bonvalot et al. 1998; Branca et al. 2003; Carbone et al. 2003b, 2006; Kazama and Okubo 2009) because of the harsh environmental conditions encountered close to the active craters, where it is difficult to obtain reliable data. Nevertheless, continuous measurements could potentially track rapid changes (from minutes to days) in subsurface mass redistribution, which are impossible to monitor using only discrete measurements.

The Istituto Nazionale di Geofisica e Vulcanologia (INGV) in Catania has been operating an array of continuously recording gravity stations in the summit area of Etna volcano since 1998 (Carbone et al. 2003b). The

\section{实}

(ㄷ) 2014 Greco et al.; licensee Springer. This is an Open Access article distributed under the terms of the Creative Commons Attribution License (http://creativecommons.org/licenses/by/2.0), which permits unrestricted use, distribution, and reproduction in any medium, provided the original work is properly credited. 
stations are equipped with spring-based relative gravimeters, which represent the best compromise in terms of quality and cost. These types of instruments can be deployed at sites very close to active craters, where significant gravity changes associated with volcanic activity are expected (Greco et al. 2008; Bonaccorso et al. 2011b, c).

Over the 2011 to 2013 period, the eruptive activity at the Etna volcano has been dominated by frequent, intermittent episodes of spectacular lava fountains associated with fast-moving lava flows and tephra columns occurring from the New SE Crater in the summit area (Ganci et al. 2012). The average duration of these paroxysmal eruptions is approximately 1 to $2 \mathrm{~h}$ (Ganci et al. 2012), with lava fountains up to 800 to $1,000 \mathrm{~m}$ high (Calvari et al. 2011) erupting approximately $1 \times 10^{6} \mathrm{~m}^{3}$ of pyroclastics and about twice as much lava (Calvari et al. 2011; Ganci et al. 2012).

Continuous observations with spring gravimeters conducted at Etna volcano during these short-lived but intense paroxysmal events have shown significant variations in the amplitude of the gravity signals, which correspond temporally with the increase in amplitude of seismic activity (Bonaccorso et al. 2011a, b). Since all relative gravimeters are more or less subject to offsets (tares) due to shock when subjected to severe vibrations for long periods of time (Seigel 1995), we investigated if the observed large gravity variations (hundreds of microgals ( $\mu \mathrm{Gal}) ; 1 \mu \mathrm{Gal}=$ $1 \times 10^{-8} \mathrm{~m} / \mathrm{s}^{2}$ ) could be ascribed not only to the subsurface mass redistribution phenomena but also to the mechanical response of the gravimeter to ground acceleration caused by seismic wave propagation, both in the vertical and in the horizontal components. In such a case, the observed gravity signal should be the combination of (i) a component due to the subsurface mass or density variations accompanying the ascent of magma to the Earth's surface and (ii) a spurious component due to the effects of transient ground acceleration caused by seismic wave propagation.

We performed extensive laboratory tests to evaluate the degree of dependence between the ground accelerations, similar to those accompanying explosive activity, and the gravimetric response of two instruments operating at Etna for volcano monitoring purposes: the LaCoste \& Romberg D\#185 (Lafayette, CO, USA), used for continuous gravity recording, and the Scintrex CG-3 M\#9310234 (Concord, ON, Canada), typically used for time-lapse surveys and occasionally deployed for continuous measurements. Here, we show the results of the characterization of these two gravimeters using a vibrating platform to induce appropriate accelerations, in both the vertical and horizontal directions, through calibrated oscillating systems. We simulated the conditions occurring during the paroxysmal events, driving the vibration platform with signals resembling the seismic sequences recorded at the Etna volcano during the recent lava fountains. Experimental results highlight that when vibration is applied to the gravimeters with amplitudes and frequencies comparable to those observed during explosive activity, significant changes in gravity readings can be recorded.

\section{Methods \\ Gravity and seismic signals recorded during the 10 April 2011 lava fountain}

Among the 46 lava fountains occurring at the New SE Crater of the Etna volcano between January 2011 and December 2013, we focused on the 10 April 2011 event, when two continuously recording gravity stations (SLN and BVD) were operative. They were situated on the southern flank of the Etna volcano (SLN at 1,740 $\mathrm{m}$ above sea level (a.s.l.) and BVD at 2,920 $\mathrm{m}$ a.s.l.), at distances of about 1 and $6 \mathrm{~km}$ from the New SE Crater, respectively (Figure 1a). The gravity stations were equipped with spring-based relative gravimeters: the LaCoste \& Romberg D\#185 at BVD and the Micro-g LaCoste gPhone\#27 at SLN (resolution better than $1 \mu \mathrm{Gal})$. At both stations, data were acquired every second, and averaged and stored every minute. Tiltmeters for measurements along two perpendicular axes and several meteorological sensors (pressure, humidity, and temperature) were also operating at the gravity stations and were used to reduce the instrumental effects from meteorological factors (Del Negro et al. 2008). Moreover, two broadband three-component seismometers (40 s; sampling rate $100 \mathrm{~Hz}$; Nanometrics Trillium, Kanata, ON, Canada) which were part of the permanent seismic network of the Etna volcano (D'Alessandro et al. 2013) were also in operation a few tens of meters from the SLN and BVD gravity stations during the 10 April 2011 lava fountain.

On the night of 9 April 2011, the explosive activity at the New SE Crater began to increase gradually, as did the amplitude of volcanic tremor recorded by the INGVCatania seismic network (Bonaccorso et al. 2011c). In the morning of 10 April, the eruptive phenomena rapidly intensified, and further significant increase in the amplitude of volcanic tremor was observed, culminating around 09:30 (all times are Universal Time Coordinated) with vigorous lava fountaining and a column of rising ash and gas. Intense eruptive activity and ash emission continued until about 14:00, followed by a rapid decline (http://www.ct. ingv.it/it/component/content/article/11-notizie/news/347).

After the removal of the Earth tides and instrumental drift effects, the raw gravity sequences from the SLN and BVD stations between 06:00 and 16:00 on 10 April 2011 showed significant variations in correspondence with the paroxysmal episode (Figure 1b,c). In particular, at SLN, an increase of the mean value of the gravity signal with a maximum amplitude of about $+50 \mu \mathrm{Gal}$ was observed from 08:48. On the other hand, at the BVD station, a more rapid and marked decrease in the gravity signal, 

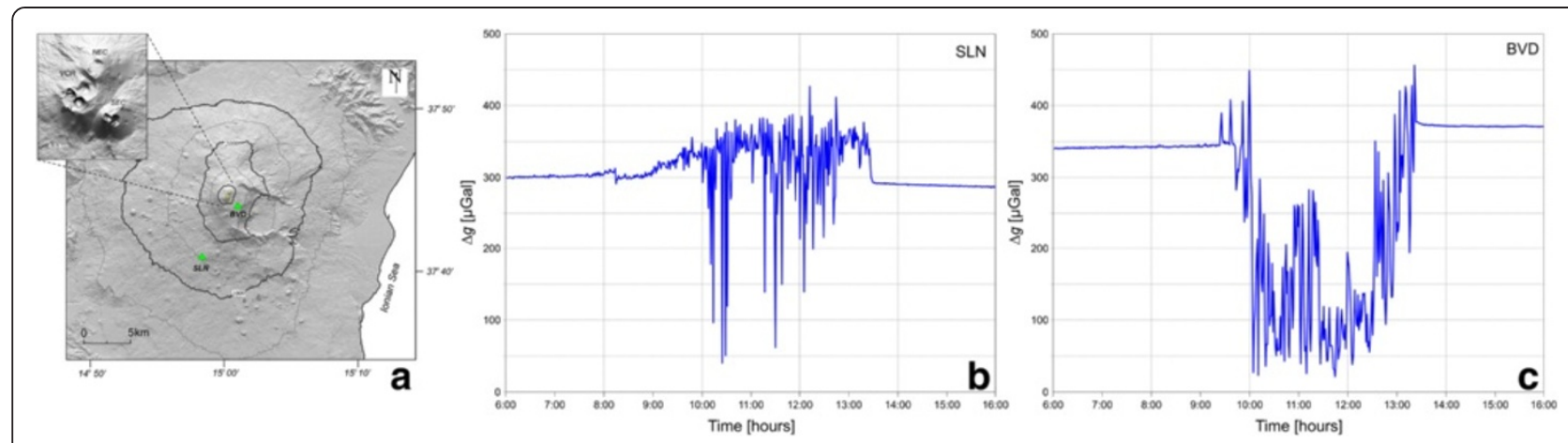

Figure 1 Digital elevation model of the Etna volcano with BVD and SLN gravity stations (green triangles). The inset in the top-left corner shows the distribution of the summit craters (a). Gravity sequences observed at (b) SLN and (c) BVD stations between 06:00 and 16:00 on 10 April 2011 after removing the effects of the Earth tides and instrumental drift.

with a maximum amplitude of about $-200 \mu \mathrm{Gal}$, was observed from 09:22. After the eruptive activity ended, no further gravity variations were detected, even if the mean values of the gravity sequences did not return to their original levels. Indeed, at SLN, the mean value was lower than about $15 \mu \mathrm{Gal}$, while at BVD, it was higher than about $+30 \mu \mathrm{Gal}$.

Figure 2a,b shows the seismic signals recorded during the paroxysmal event at the two seismic stations at the BVD and SLN sites. A comparative analysis performed on the gravity data recorded at SLN and BVD, and the modulus of the three-component seismic signals calculated as the vector summation of the three seismic components, appropriately rescaled and minutely averaged, revealed a strong correlation between the sequences (Figure 3). In particular, the gravity signals were more amplified when the greater seismic amplitudes were observed, and a quadratic relationship between the gravity and the seismic signals was observed at both stations during the paroxysmal event (Figure 3c,d). However, at the BVD station, besides a sign inversion, there was also a delay of about 100 min between the increases of the seismic signals with respect to the gravity variations.

Figure 4 shows the $x$ (east-west), $y$ (north-south), and $z$ (up-down) components of the acceleration (obtained by the first derivative of the seismic velocity data) acquired during the eruptive event at SLN and BVD. Thus, it is also possible to estimate the threshold of acceleration needed to induce the gravimeter response at the two gravity stations: about $1 \times 10^{-4} \mathrm{~m} / \mathrm{s}^{2}\left(10 \mu \mathrm{g} ; 1 \mathrm{~g}=9.8 \mathrm{~m} / \mathrm{s}^{2}\right)$ at BVD and about $1 \times 10^{-5} \mathrm{~m} / \mathrm{s}^{2}(1 \mu \mathrm{g})$ at SLN. These values of acceleration were reached at about 09:30 at BVD and at about 08:00 at SLN.

The spectrograms of the inertial acceleration data (Figure 5) show that most of the frequency content of the signal is lower than $5 \mathrm{~Hz}$ and increases during the

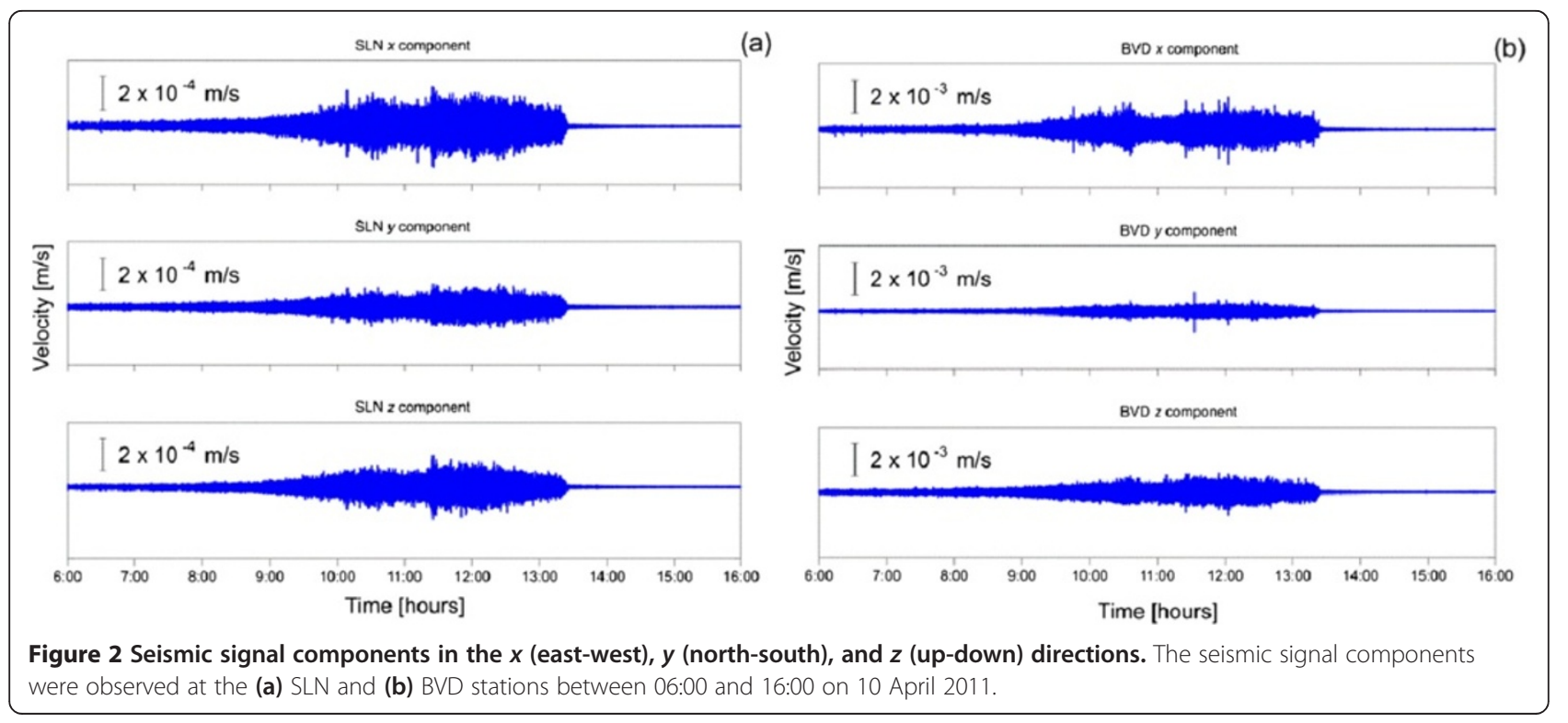



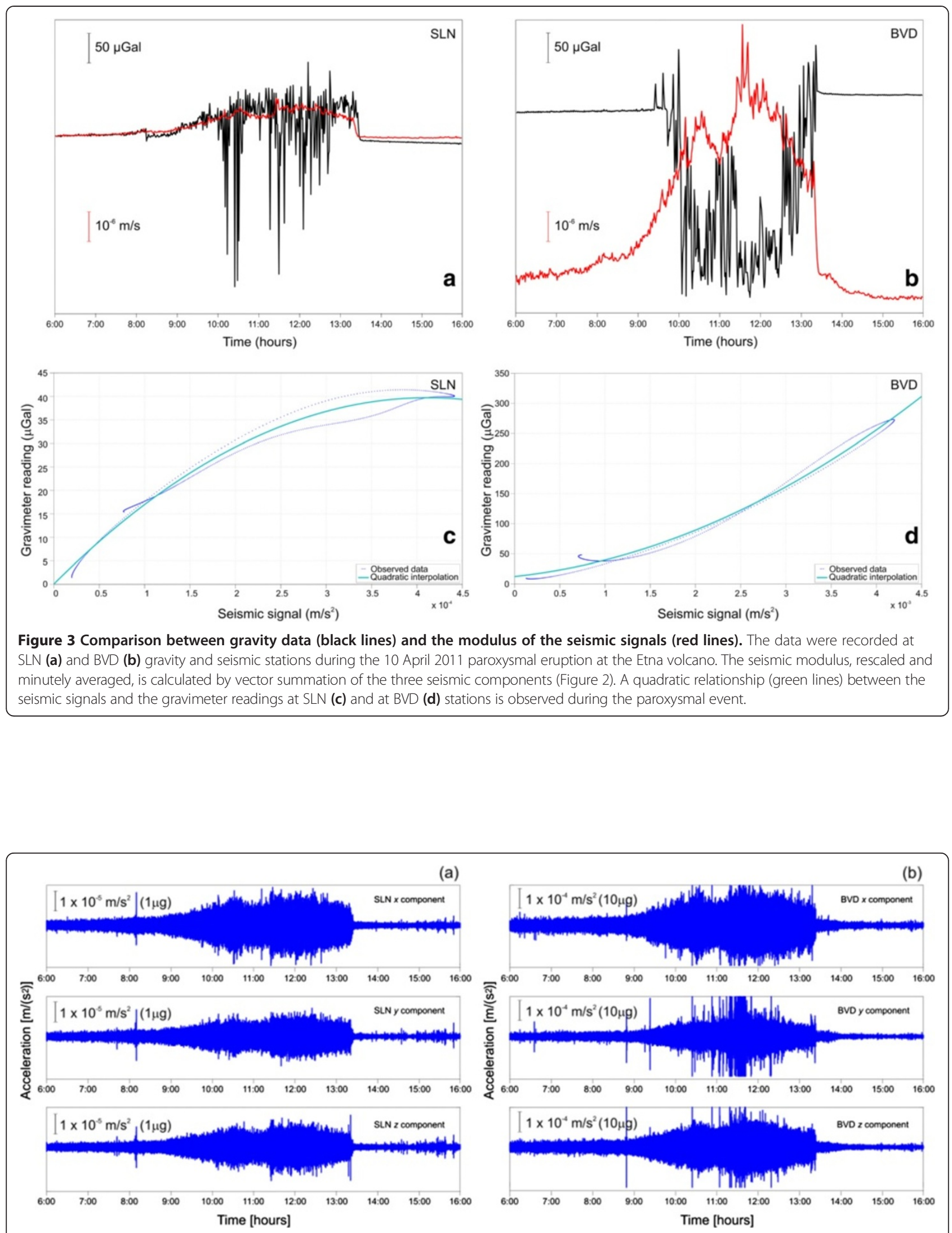

(a)

(b)

Figure 4 Components $\boldsymbol{x}, \boldsymbol{y}$, and $\boldsymbol{z}$ of the inertial acceleration. SLN (a) and BVD (b) seismic stations between 06:00 and 16:00 on 10 April 2011. 


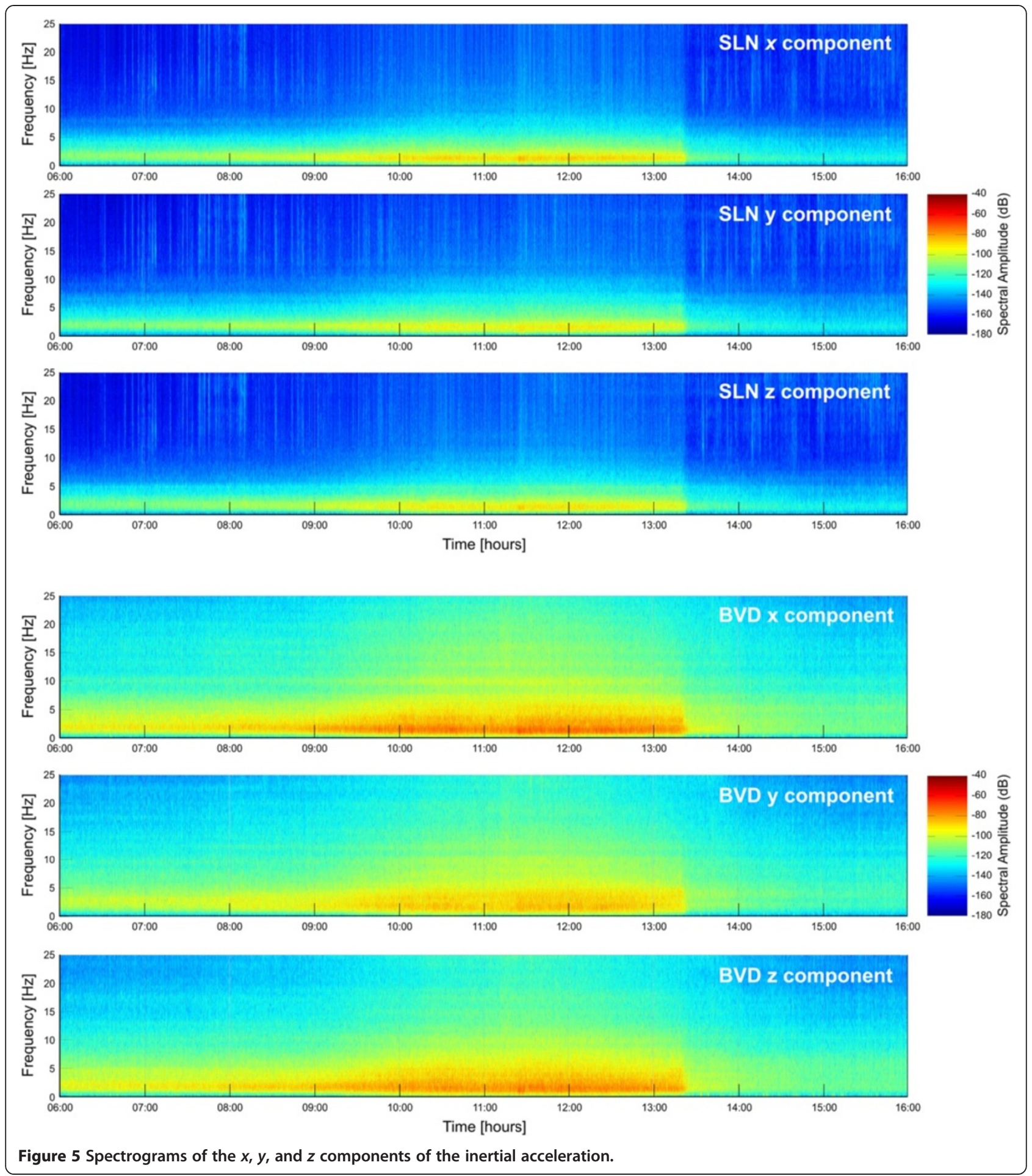

paroxysmal events. The comparison between the seismic signals at the two stations (Table 1) indicates that the amplitude at BVD is about 1 order of magnitude greater than that recorded at SLN, probably because BVD is closer than SLN to the eruptive vent (Figure 1a).

\section{Ground vibrations and gravimeter response}

Several studies have been carried out that take into account gravity changes detected during different eruptive events at the Etna volcano (Branca et al. 2003; Carbone et al. 2006; Bonaccorso et al. 2011a, b). Essentially, the 
Table 1 Maximum peak-to-peak acceleration values

\begin{tabular}{lcc}
\hline Component & SLN (mg) & BVD (mg) \\
\hline$a_{x, p-p}$ & 0.418 & 3.172 \\
$a_{y, p-p}$ & 0.285 & 4.699 \\
$a_{z, p-p}$ & 0.316 & 3.629 \\
\hline
\end{tabular}

For the $x$ (east-west), $y$ (north-south), and $z$ (up-down) acceleration components at the SLN and BVD seismic stations.

observed gravity changes were interpreted as being due to local mass redistributions triggered by the magma/gas dynamics in the shallow portion of the volcano's plumbing system. Nevertheless, the ascent of magma to the Earth's surface and its eruption are commonly accompanied by earthquakes and seismic tremor, resulting in ground vibrations (Alparone et al. 2003; Cannata et al. 2008) which may affect the measurement system of a spring gravimeter. It is well known that relative spring gravimeters, when subjected to shocks, can react with a sudden change in the reading level (tares). The possibility that ground vibration might contribute to the noise level of gravimeter measurements has already been suggested by Greco et al. (2008). However, although instrumental effects can occur during volcanic processes, the effects have never been quantified until now.

The vibrating platform is an ideal tool to characterize the dynamic behavior of the mechanical components of gravity instruments (Tobyáš et al. 1999; Aliod et al. 2003). We calibrated the spring gravimeters by analyzing their response to controlled harmonic accelerations exerted by the vibrating platform. The amplitude-frequency analysis allows investigation of the dynamic response of the gravimeters at specific frequencies and determination of the critical resonance frequencies.

The vibrating platform tests have been explicitly designed to reproduce some specific frequencies and calibrated accelerations along the $x, y$, and $z$ directions (corresponding to east-west, north-south, and up-down directions; Figure 6), observed in the seismic signals during paroxysmal events at Etna. The device used for the tests is composed of several elements: a shaker (consisting of a movable aluminum platform activated using piezoelectric actuators), a power amplifier, a function generator, displacement detectors, and a vibration regulator. The signals driving the vibration platform are generated by linear actuators capable of producing accelerations in the frequency band $10^{-2}$ to $10^{2} \mathrm{~Hz}$, with amplitudes ranging between $10^{-8}$ and $50 \times 10^{-3} \mathrm{~g}$.

This vibrating platform is shown in detail in Figure 6. The aluminum platform is placed on a yielding support to allow horizontal displacements under the action of the piezoelectric actuators and is a 'quasi-stable' support in the absence of excitations. The function generator provides the appropriate waveforms, which are suitably amplified by the power amplifier and then used to drive the piezoelectric actuators. The function generator allows us to drive the vibrating platform with a periodic sine wave motion with different amplitude and frequency values.

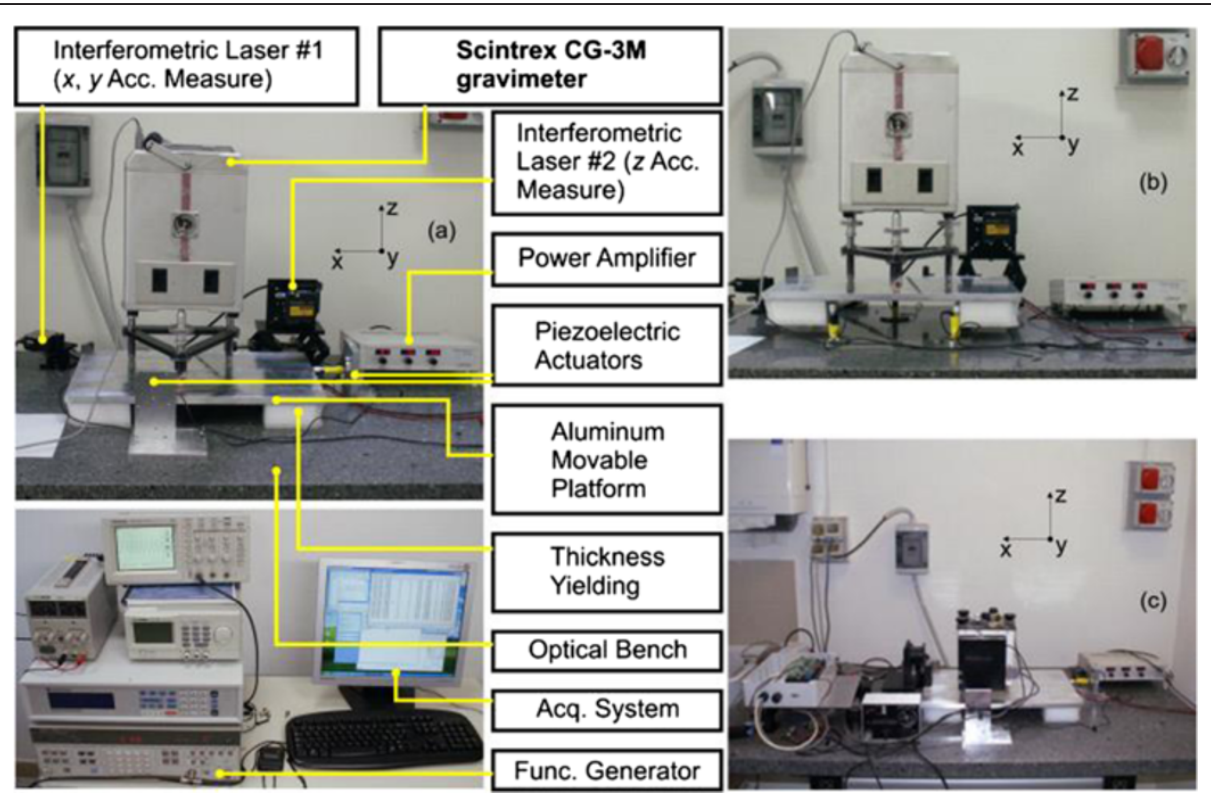

Figure 6 Laboratory equipment. Facility (a) used to test along the $x, y$, and $z$ directions to determine the decoupling coefficient between high-frequency vertical and horizontal accelerations and the response of the Scintrex CG-3 M\#9310234 (b) and LaCoste \& Romberg D\#185 gravimeters $\mathbf{( c )}$. The figures show the piezoelectric actuators placed below (b) and lateral to (c) the movable platform to induce vertical and horizontal accelerations, respectively. The vibration directions of the platform are also shown. 
The displacement measurements are made by a pair of high-precision interferometric lasers (Keyence, Osaka, Japan), which measure the platform displacements along the horizontal (laser \#1) and vertical (laser \#2) directions. The vibration regulator, comprising an acquisition system and a personal computer, allows us to evaluate the accelerations, in both the time and frequency domains, to which the platform and the instrument are subjected. The whole device is placed on an optical bench.

To characterize the gravimeter's response to ground vibrations, we investigated the coupling factor between the amplitude response (in the $z$ direction) of the LaCoste \& Romberg D\#185 and Scintrex CG-3 M\#9310234 springbased relative gravimeters and the controlled vibrations in the $x, y$, and $z$ directions. The coupling factor $K$ is defined by the following equation:

$$
K_{(i) z}(f)=\left|\frac{a_{z}(f)}{b_{(i)}(f)}\right|
$$

where $a_{z}$ is the output signal of the gravimeter (in milligal $(\mathrm{mg}))$, and $b_{(i)}$ is the amplitude of the $i$ th excitation signal (in $\mathrm{mg}$ ); $i$ stands for any horizontal $(h)$ and vertical $(z)$ component. High coupling factor values indicate the frequencies at which there is a maximum transfer of spurious signals in the gravimeter response (resonance frequencies). To determine the factors $K_{(h) z}$, the movable aluminum platform was excited simultaneously along the $x$ and $y$ directions by the horizontal actuators, and laser \#1 was used to measure the induced displacement (Figure 6a). In this case, laser \#2 was used only to monitor possible undesired movements in the vertical component of the platform. To determine the coupling factor $K_{(z) z}$, the experimental setup, appropriately modified by moving the piezoelectric actuators below the aluminum platform, allows forcing of the vibration platform in the $z$ direction and measuring the induced displacements using laser \#2.

\section{Results and discussion Laboratory tests}

We simulated the performance of relative gravimeters in the laboratory by exposure to forced vibrations at intensities and frequencies that can be encountered in the near field during paroxysmal events. The vibrating platform was driven on the basis of the peak-to-peak values estimated in the $x, y$, and $z$ acceleration components at the SLN and BVD stations derived from seismic signals (Table 1). According to the analyses results, and considering the limit of the equipment, the amplitude values of the inertial acceleration (ranging between 0.18 and $3.5 \mathrm{mg}$ ) were produced by moving the platform by a few tens of micrometers. Furthermore, to excite any possible
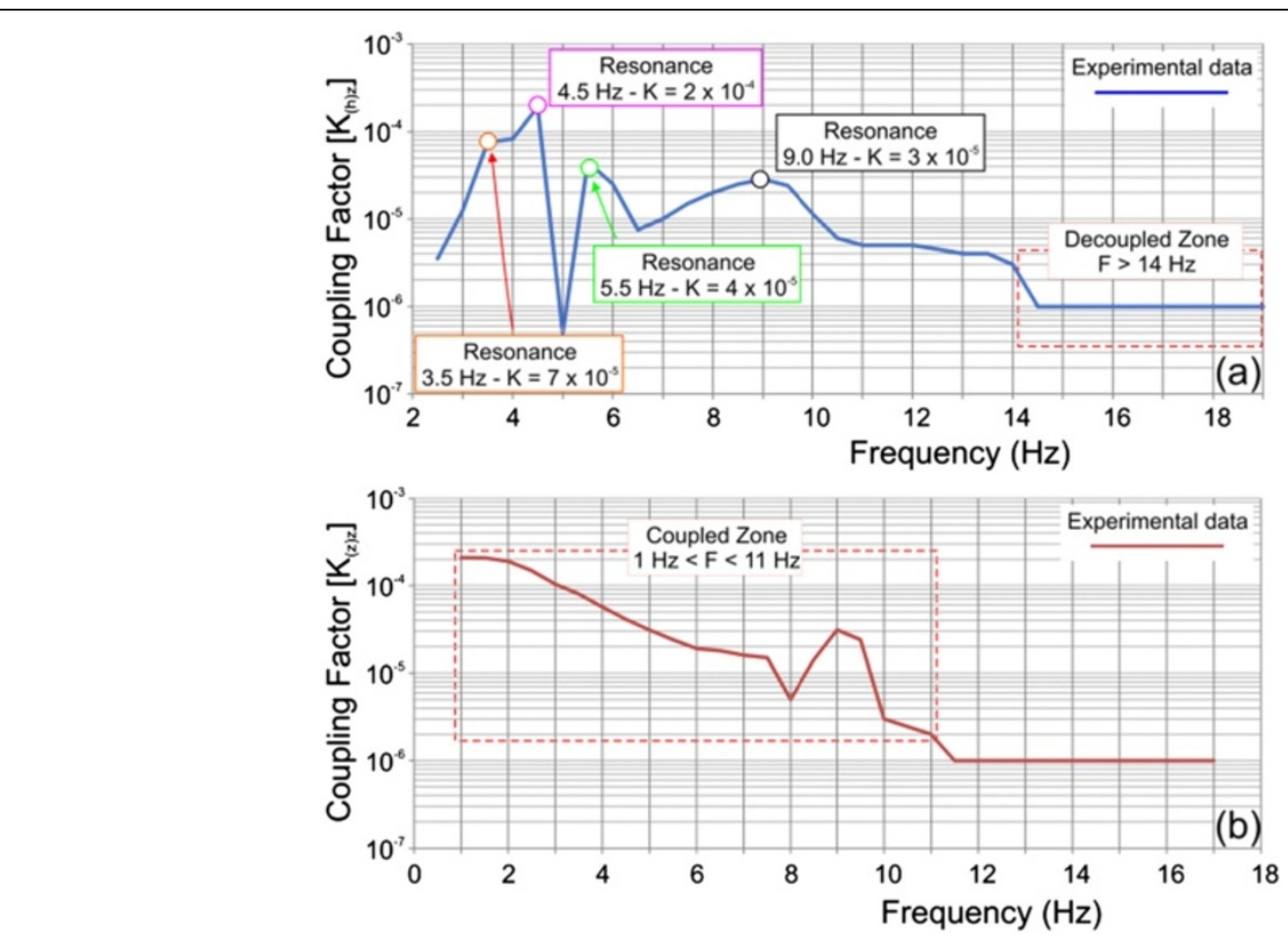

Figure 7 Coupling factors $K_{(h) z}(a)$ and $K_{(z) z}(b)$ of the LaCoste \& Romberg D\#185 gravimeter. The factors were calculated considering the instrumental response and the amplitude of the horizontal (a, vibration amplitude $2 \mathrm{mg}$ ) and vertical (b, vibration amplitude $1.0 \mathrm{mg}$ ) excitations at different frequencies. 
Table 2 Frequency values corresponding to the maximum coupling between excitation and LaCoste \& Romberg D\#185 response

\begin{tabular}{lc}
\hline Frequency $(\mathrm{Hz})$ & Coupling factor $\boldsymbol{K}_{(\boldsymbol{h}) \mathbf{z}}$ \\
\hline 3.5 & $7 \times 10^{-5}$ \\
4.5 & $2 \times 10^{-4}$ \\
5.5 & $4 \times 10^{-5}$ \\
9.0 & $3 \times 10^{-5}$ \\
\hline
\end{tabular}

resonances in the sensors, the tests were performed in the frequency range between 1 and $25 \mathrm{~Hz}$, which are the dominant frequencies of the seismic signals during paroxysmal events.

In order to evaluate the gravimeter response as a function of the horizontal and vertical excitations $(x, y$, and $z$ ), the laboratory test can be divided into three different steps: during the first step, the excitation was switched off; then, in the second step, the platform was forced to move with a horizontal or vertical displacement; finally, in the third step, the excitation was switched off again. Below, we describe the details of the laboratory tests that were performed by applying controlled vibrations in the horizontal and vertical directions to the LaCoste \& Romberg D\#185 and Scintrex CG-3 M\#9310234 gravimeters.

\section{LaCoste \& Romberg D\#185 gravimeter}

We were particularly interested in investigating the dependence of the LaCoste \& Romberg D\#185 on the vibrations because this gravimeter was in operation at the Etna BVD station (Figure 1a) during the 10 April 2011 lava fountain. During the tests, the gravity data were acquired every second. The average over 60 measurements was then calculated and stored in the solid-state memory of a CR10X Campbell Scientific data logger (at 1 datum/min; Logan, UT, USA). The tidal effect correction was performed a posteriori with additional software.
Together with the gravimetric data, the instrument also provided the measurement of the tilt angles of its base. Figure $6 \mathrm{c}$ shows the experimental setup with the arrangement of the gravimeter and the data logger.

Amplitude values ranging between 2 and $3.5 \mathrm{mg}$, produced by imposing platform movements around a few tens of micrometers in the frequency range between 2 and $19 \mathrm{~Hz}$, were taken into account, reproducing the amplitudes and frequencies typical of those recorded at the BVD gravity station during the Etna paroxysmal events.

Figure 7 a shows the coupling factor values obtained with respect to the horizontal excitation frequency. A coupled zone is evident at frequencies ranging between 2.5 and $14 \mathrm{~Hz}$, with four frequencies at which there was maximum dependence (Table 2). At frequencies higher than $14 \mathrm{~Hz}$, the dependence was not significant, which means that there was minimal transfer of spurious signals in the gravimeter response (a decoupling zone). The different resonance peaks were most probably caused by the different couplings among the mechanical components of the gravimeter.

Table 2 reports the values of the resonance frequencies, together with the obtained coupling factors. In particular, at the frequency of $4.5 \mathrm{~Hz}$, the coupling factor was extremely high $\left(2 \times 10^{-4}\right)$.

Figure $7 \mathrm{~b}$ shows the coupling factor $K_{(z) z}$ calculated for the LaCoste \& Romberg D\#185 gravimeter with respect to different vertical excitation frequencies. The results show that the coupling factor was significant in the range of 1 to $11 \mathrm{~Hz}$, but rapidly decreased at frequencies higher than $11 \mathrm{~Hz}$ (the decoupled zone). The coupling factor is directly related to the excitation frequency, but in this case, there were no peaks of maximum dependence such as those observed for the horizontal excitations.

Figure 8 reports the response of the gravimeter when subjected to accelerations along the horizontal axes $(x$ and $y$ ), in the frequency band between 2.5 and $19 \mathrm{~Hz}$, and excitations with amplitudes ranging between 2 and

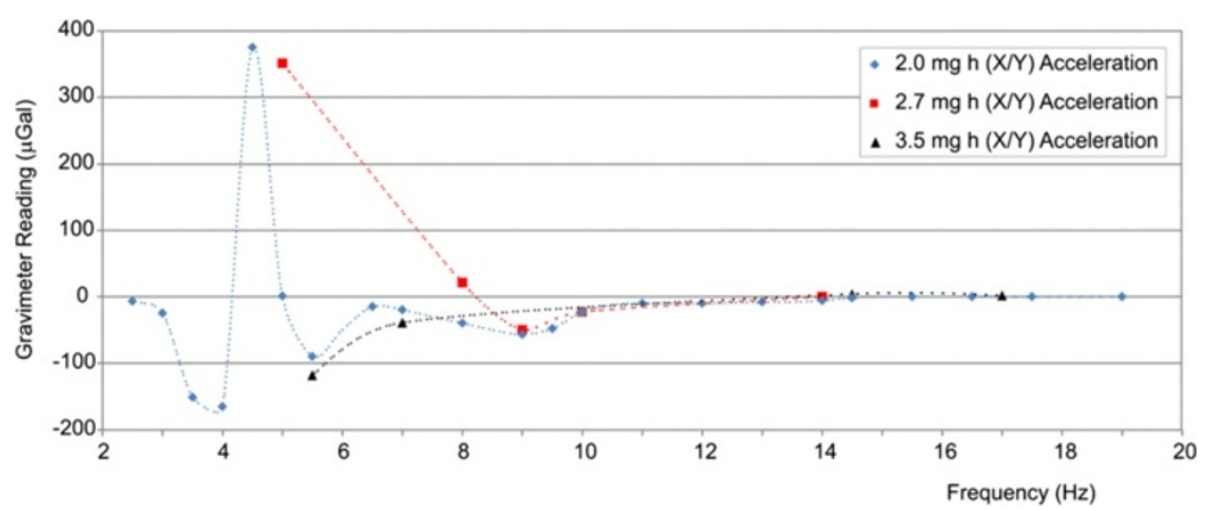

Figure 8 Response of the LaCoste \& Romberg D\#185 gravimeters horizontally excited. The excitation was performed with signals of $2.0 \mathrm{mg}$ (blue rhombuses), 2.7 (red squares), and $3.5 \mathrm{mg}$ (black triangles) amplitudes (typical amplitude value recorded at BVD station during paroxysmal events), varying in frequency between 2 and $20 \mathrm{~Hz}$. 

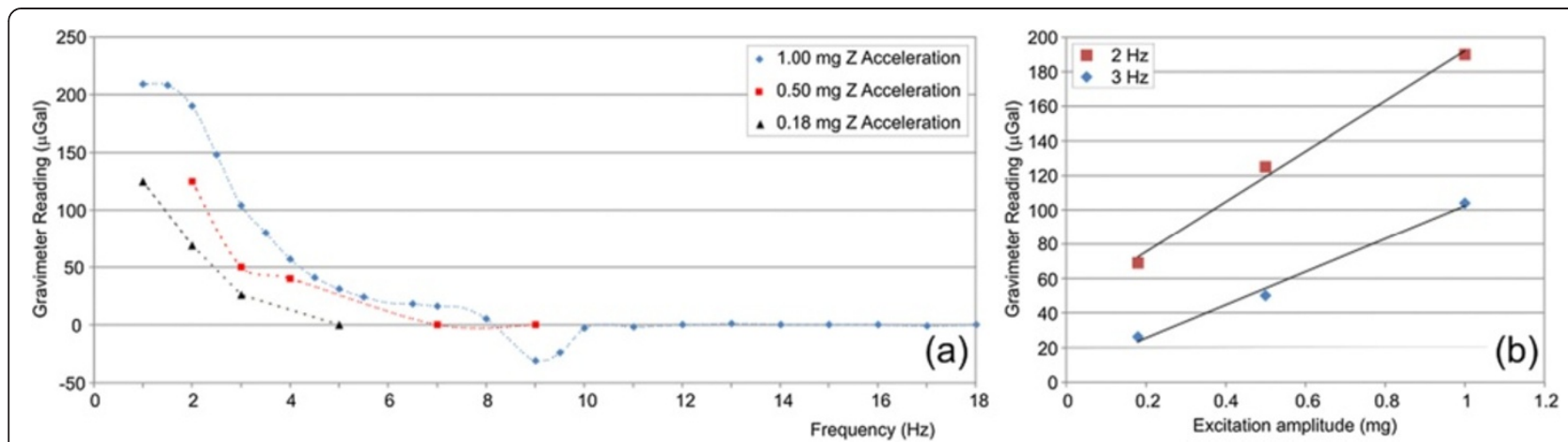

Figure 9 Response of the LaCoste \& Romberg D\#185 gravimeters for different vertical excitation frequencies and amplitudes. The blue rhombuses are obtained by moving the vibration platform in the vertical direction with a frequency signal between 1 and $18 \mathrm{~Hz}$ and amplitude equal to $1 \mathrm{mg}$. The red squares and black triangles indicate amplitude movements of 0.5 and $0.18 \mathrm{mg}$, respectively (a). A linear relationship is found between the gravity readings and the excitation amplitudes at 2 and $3 \mathrm{~Hz}$ (b).

$3.5 \mathrm{mg}$. In agreement with the coupling factor characterization (Figure 7a), in all cases tested, the gravimeter dependence on the horizontal excitation frequency was significant in the frequency range between 2.5 and $14 \mathrm{~Hz}$ (Figure 8 ). It can also be seen that the maximum dependence of the gravimeter was in the range of frequencies between 3.5 and $5.5 \mathrm{~Hz}$. Maximum dependency was observed at the frequencies of $4.5 \mathrm{~Hz}$ (acceleration equal to $2.0 \mathrm{mg}$ ) and $5 \mathrm{~Hz}$ (acceleration equal to $2.7 \mathrm{mg}$ ). Moreover, for the accelerations of 2.0 and $3.5 \mathrm{mg}$, the gravimeter output also showed a sign inversion. At frequencies higher than $14 \mathrm{~Hz}$, the gravimeter exhibited minimal dependence on all the imposed accelerations (coupling factor values are low).

We also evaluated the response of the gravimeter to the vertical excitation at different frequencies and amplitudes. Figure $9 \mathrm{a}$ shows the gravity readings as a function of vertical excitations in the frequency band between 1 and $18 \mathrm{~Hz}$, and with amplitudes ranging between 0.18 and $1.0 \mathrm{mg}$. The results confirm that the maximum
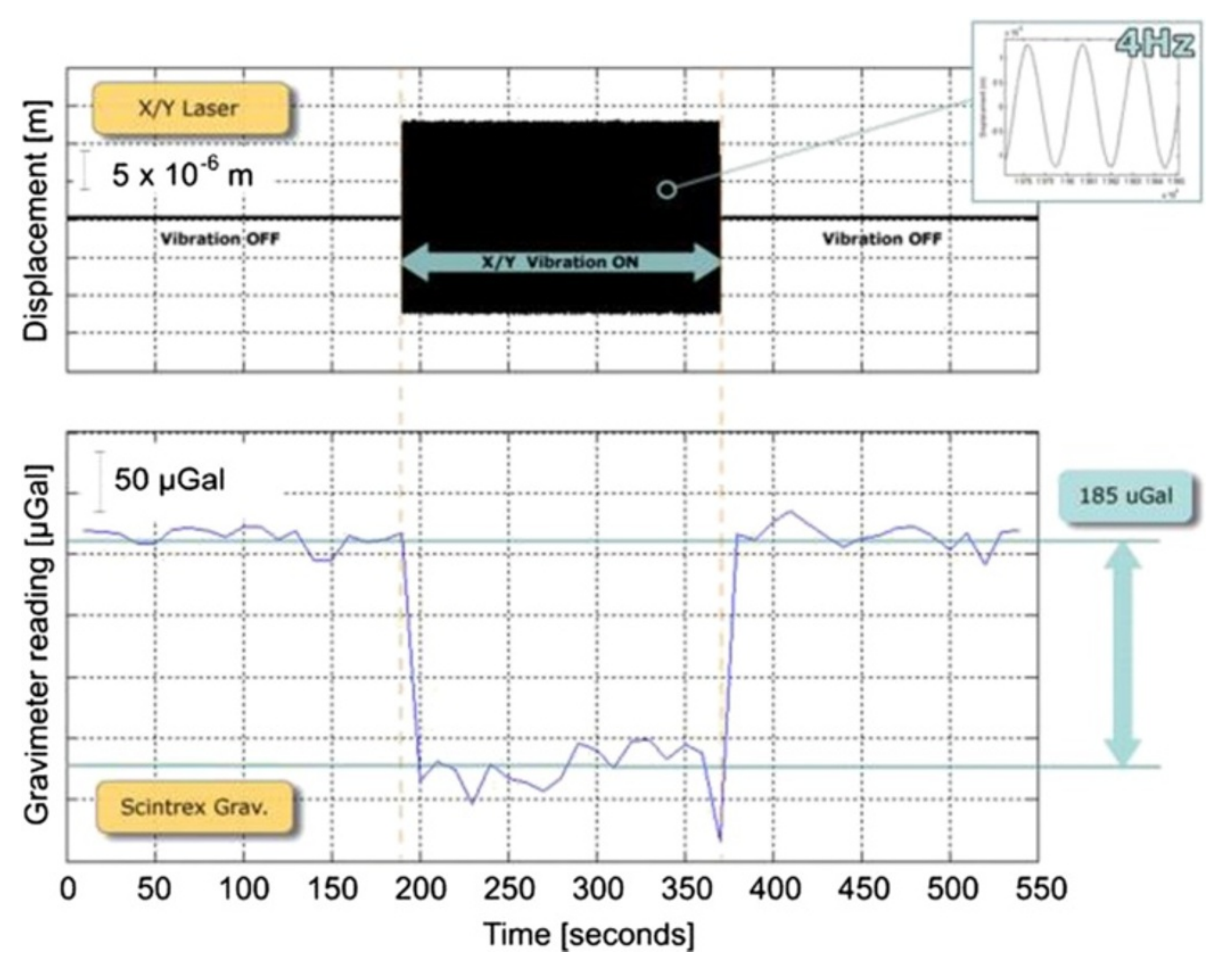

Figure 10 Characterization tests of the Scintrex CG-3 M\#9310234 gravimeter. Horizontal displacements of the vibrating platform (top) and gravimeter response acquired simultaneously (bottom). In the time indicated by the dotted lines, the platform was moved with horizontal displacements of $25 \mu \mathrm{m}$ at a frequency of $4 \mathrm{~Hz}$. 


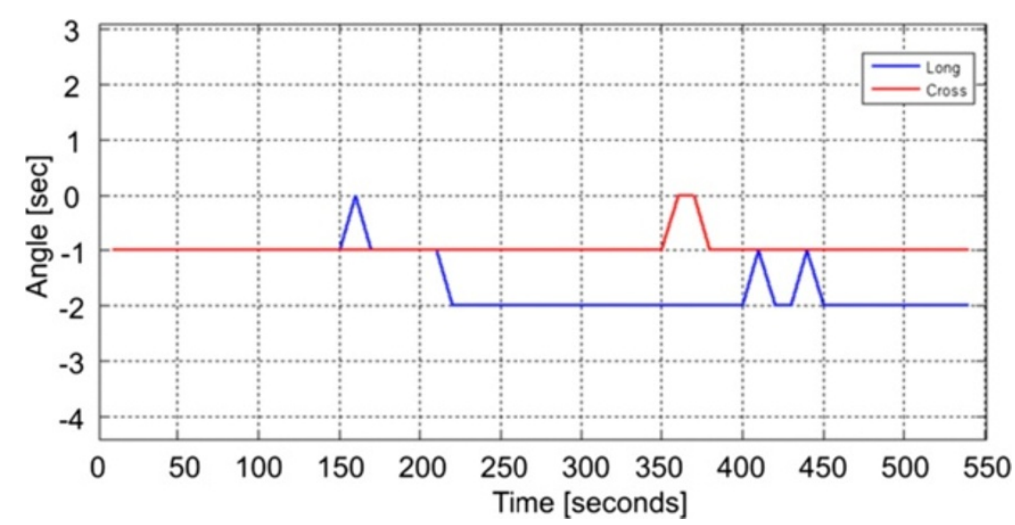

Figure 11 Outputs of the two inclinometers of the Scintrex CG-3 M\#9310234 gravimeter. The signals were acquired simultaneously to characterization at $4 \mathrm{~Hz}$. It is evident that during this phase, the instrument has not undergone inclinations.

dependence of the gravimeter on the vertical excitations occurred at frequencies between 1 and $11 \mathrm{~Hz}$. The dependence was negligible for higher frequencies investigated. Furthermore, a linear relationship between the gravity output and the amplitude of excitation signal was found, as shown by the linear fit for the frequencies of 2 and $3 \mathrm{~Hz}$ in Figure 9b.

\section{Scintrex CG-3 M\#9310234 gravimeter}

During the characterization tests of the Scintrex CG$3 \mathrm{M} \# 9310234$ gravimeter (Figure $6 \mathrm{~b}$ ), the output digital data were recorded at a frequency of $0.1 \mathrm{~Hz}$, by averaging four samples. The data were automatically corrected for the tidal effect. In addition, the tilt sensors, embedded in the gravimeter, provided the measurement of the displacements of its base. Figure 10 shows that during the excitation phase, which lasted about $200 \mathrm{~s}$, with a horizontal displacement of $25 \mu \mathrm{m}$ at a frequency of $4 \mathrm{~Hz}$ (equivalent to an acceleration of $\left.7.8 \times 10^{-3} \mathrm{~m} / \mathrm{s}^{2}=0.8 \mathrm{mg}\right)$, the gravimeter exhibited a negative offset with an amplitude of about $185 \mu \mathrm{Gal}(189 \times$ $10^{-6} \mathrm{mg}$ ). At the end of the excitation phase, the gravity output returned to its original level. The coupling factor
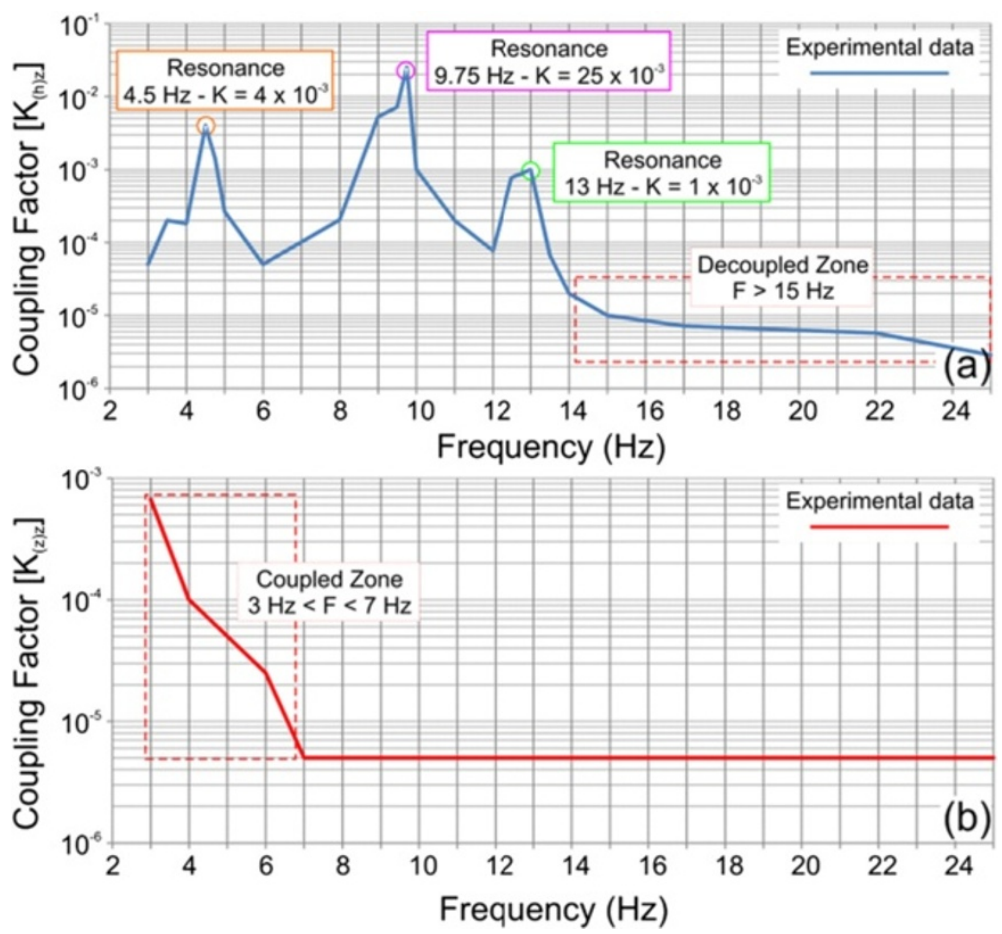

Figure 12 Coupling factors $K_{(h) z}(\mathrm{a})$ and $K_{(z) z}$ (b) of the Scintrex CG-3 M\#9310234 gravimeter. The factors were calculated considering the instrumental response and the amplitude of the horizontal (a, vibration amplitude $1.0 \mathrm{mg}$ ) and vertical (b, vibration amplitude $0.5 \mathrm{mg}$ ) excitations at different frequencies. 
Table 3 Frequency values corresponding to the maximum coupling between excitation and Scintrex CG-3 M response

\begin{tabular}{lc}
\hline Frequency $(\mathbf{H z})$ & Coupling factor $\boldsymbol{K}_{(\boldsymbol{h}) \mathbf{z}}$ \\
\hline 4.5 & $4 \times 10^{-3}$ \\
9.75 & $25 \times 10^{-3}$ \\
13 & $1 \times 10^{-3}$ \\
\hline
\end{tabular}

$K_{(h) z}$ for the gravimeter (given by the ratio of the gravimeter response to the amplitude of the horizontal acceleration at $4 \mathrm{~Hz}$; see Equation 1) is equal to

$$
K_{(h) z}(4 \mathrm{~Hz})=\frac{189.10^{-6}}{0.8}=236.10^{-6}
$$

Figure 11 shows the output of the two Scintrex CG$3 \mathrm{M}$ inclinometers acquired during the characterization; it is evident that the instrument did not undergo any significant inclination during the test. This information enables us to exclude the effect of inclination on the gravity measurements.
To investigate the performances of the gravimeter at different excitation frequencies, the coupling factor was characterized by varying the excitation frequency in the range between 3 and $25 \mathrm{~Hz}$. Figure 12a shows the coupling factor values obtained with respect to the horizontal excitation frequency. It is worth noting that there are three frequencies for which there is a maximum peak of dependence (resonance frequencies); at frequencies higher than $14 \mathrm{~Hz}$, the dependence is not significant (indicating the decoupling zone). Table 3 reports the values of the resonance frequencies together with the obtained coupling factors. In particular, at the frequency of $9.75 \mathrm{~Hz}$, the coupling factor is extremely high $\left(25 \times 10^{-3}\right)$; thus, any signal present at this frequency would be apparent in the gravimeter response, amplified by a factor of 0.025 .

The Scintrex CG-3 M gravimeter was also tested to determine the coupling factor for the vertical excitation (Figure 12b). We investigated the same levels of acceleration as for the horizontal excitation tests. Figure 12b shows a plot of the coupling factor $K_{(z) z}$ calculated for the Scintrex CG-3 M gravimeter with respect to different vertical excitation frequencies. The results show that the coupling factor was higher for frequencies in the
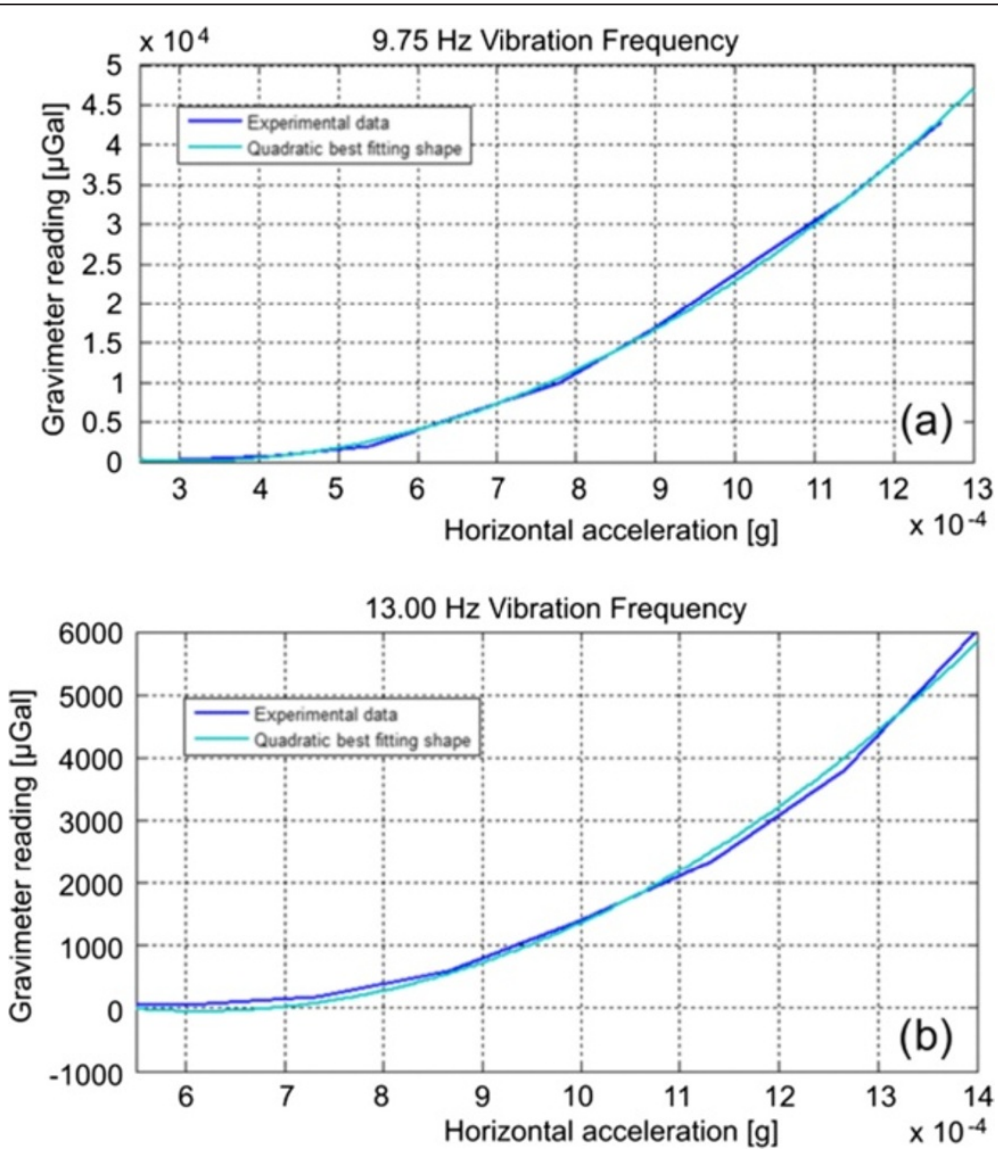

Figure 13 Response of the Scintrex CG-3 M\#9310234 gravimeter with respect to different horizontal excitation amplitudes. The gravimeter response was tested at the fixed frequencies of $9.75 \mathrm{~Hz}$ (a) and $13 \mathrm{~Hz}$ (b). 
range of 3 to $7 \mathrm{~Hz}$, but lower than the coupling factor for the horizontal excitation (Figure 12a). The coupling factor values decreased rapidly at frequencies higher than $7 \mathrm{~Hz}$ (the decoupled zone). Figure 13 shows the Scintrex CG-3 M gravimeter output with respect to the different amplitude values of the horizontal excitation at the fixed frequencies of 9.75 and $13 \mathrm{~Hz}$. In both cases, it is evident that the relationship between the gravity and acceleration signals is nonlinear and is best fitted by a quadratic polynomial function.

\section{Conclusions}

Exploiting the gravity temporal sequences collected at the Etna volcano during a short-lived but violent lava fountain at two sites very close to the eruptive vent, we conducted laboratory tests to investigate on the instrumental effects due to the ground vibrations that accompanied the explosive activity. The tests were focused on identifying the coupling factors between the gravimeter responses (in the $z$ direction) and the controlled vibrations in the $x, y$, and $z$ directions, at the frequencies and amplitudes observed in the seismic waves recorded at the Etna volcano during the lava fountains. In this way, we determined the vibration frequencies to which there was a maximum transfer of spurious signals in the gravity output. Amplitude values ranging between 0.18 and $3.5 \mathrm{mg}$, produced by imposing platform movements around a few tens of micrometers in the frequency range between 1 and $25 \mathrm{~Hz}$, were taken into account. The results revealed different behaviors and a marked sensitivity of the LaCoste \& Romberg D\#185 and Scintrex CG-3 M\#9310234 gravimeters when subjected to vibrations of a few tens of micrometers, both in the horizontal and vertical directions. Both instruments showed a coupling zone in the frequency range between 2.5 and $14 \mathrm{~Hz}$ for the horizontal excitations. The maximum coupled zone was in the frequency range between 1 and $7 \mathrm{~Hz}$ for the vertical oscillations affecting the Scintrex CG-3 M\#9310234 and between 1 and $11 \mathrm{~Hz}$ for the vertical oscillations affecting the LaCoste \& Romberg D\#185.

The laboratory results highlighted that vibrations resembling the seismic waves propagated during paroxysmal events drive the gravimeters to their main resonant frequencies, causing an amplitude response in the gravity readings on the order of several hundred $\mu \mathrm{Gals}$, comparable to those observed during paroxysmal episodes. The laboratory tests were aimed at validating the hypothesis that seismic waves such as those recorded during the explosive activity, in both the horizontal and vertical directions, can cause significant offsets in the gravity measurement as a consequence of the nonlinear effects on the instruments. This dependence, in the first instance, can be considered quadratic (the gravimeter responds quadratically to an increase in the amplitude of the frequency excitations). This effect is mainly due to amplitude modulation of the seismic waves propagating during the event at certain frequencies. The modulating signal, through the nonlinearity, is transferred to the measurement band of the gravimeters, causing a significant apparent variation. Throughout the tests, the vibration platform was driven using an acceleration signal equivalent to those recorded by seismometers during the 10 April 2011 eruptive event at Etna. Clearly, in the real case, the envelope of the seismic signals, a packet of modulated waves, plays the main role instead of a specific and fixed carrier, as used in the tests.

The nonlinearity of the effects restricts the possibility of finding a linear transfer function from the excitation signal in the $x, y$, and $z$ directions due to the ground motion, to the gravimetric response. Moreover, due to the complicated dependence of the response of the gravimeters on the frequencies and amplitude of the input signals, it is very difficult to filter the spurious signals from the gravity sequences using the seismic signal acquired simultaneously with the gravity signal.

Our experiment results indicate that the use of continuously recording spring-based gravimeters to monitor the volcanic activity requires some precautions. Specifically, to reduce the dependence of the relative spring gravimeters on vibrations such as those recorded during the explosive activity that produces lava fountains, some $a$ priori and a posteriori techniques should be adopted to separate the gravity reading into an instrument-dependent signal (i.e., due to the mechanical perturbation of the sensor caused by seismic waves) and volcano-related components. For example, among the a priori techniques, a hardware damper system could be implemented as a support for the spring gravimeter; in this way, the high-frequency components in the three directions $(x, y$, and $z$ ) that can affect the gravimeters could largely be filtered out. For the a posteriori solutions, an approach based on neural networks could be developed to evaluate the instrumental response to the ground acceleration acting on spring gravimeters at different frequencies and amplitudes.

\section{Competing interests}

The authors declare that they have no competing interests.

\section{Authors' contributions}

FG coordinated the research, participated in the laboratory tests, and drafted the manuscript. VI and EF implemented the laboratory equipment and participated in the laboratory tests. AP participated in the laboratory tests and drafted the manuscript. GC, RN, $A B$, and CDN participated in the discussion of the results and helped draft the manuscript. All authors read and approved the final manuscript.

\section{Acknowledgements}

The final form of this manuscript benefited from the constructive comments of anonymous reviewers. The work was developed within the framework of TecnoLab, the Laboratory for Technological Advance in Volcano Geophysics, 
organized by INGV-CT and UNICT. We are also indebted to Salvatore Alparone for providing seismic data.

\section{Author details}

${ }^{1}$ Istituto Nazionale di Geofisica e Vulcanologia, Sezione di Catania, Osservatorio Etneo, Piazza Roma 2, Catania 95125, Italy. ${ }^{2}$ Istituto Nazionale di Astrofisica, Istituto di Astrofisica e Planetologia Spaziali, Via del Fosso del Cavaliere 100, Rome 00133, Italy. ${ }^{3}$ INAF Spin-Off Company, A.G.I. s.r.l, Via Enrico Stevenson 1, Monte Porzio Catone, Rome 00133, Italy. ${ }^{4}$ Dipartimento di Ingegneria Elettrica, Elettronica e Informatica, Università di Catania, Viale Andrea Doria 6, Catania 95125, Italy.

\section{Received: 4 December 2013 Accepted: 15 May 2014} Published: 29 May 2014

\section{References}

Aliod D, Mann E, Halliday M (2003) LaCoste \& Romberg air-sea gravity meter vibration tests. http://www.microglacoste.com/pdf/vibrationtest.pdf. Accessed 07 Dec 2012

Alparone S, Andronico D, Lodato L, Sgroi T (2003) Relationship between tremor and volcanic activity during the Southeast Crater eruption on Mount Etna in early 2000. J Geophys Res 108(B5):2241, doi:10.1029/2002JB001866

Battaglia M, Segall P, Roberts C (2003) The mechanics of unrest at Long Valley Caldera, California: 2. Constraining the nature of the source using geodetic and micro-gravity data. J Volcanol Geotherm Res 127:219-245

Berrino G (2000) Combined gravimetry in the observation of volcanic processes in Southern Italy. J Geodyn 30:371-388

Berrino G, Corrado G, Magliulo R, Riccardi U (1997) Continuous record of the gravity changes at Mt Vesuvius. Ann Geophys 40:1019-1028

Berrino G, Corrado G, Riccardi U (2006) On the capability of recording gravity stations to detect signals coming from volcanic activity: the case of Vesuvius. J Volcanol Geotherm Res 150:270-282, doi:10.1016/j.jvolgeores.2005.07.015

Bonaccorso A, Bonforte A, Currenti G, Del Negro C, Di Stefano A, Greco F (2011a) Magma storage, eruptive activity and flank instability: inferences from ground deformation and gravity changes during the 1993-2000 recharging of Mt. Etna volcano. J Volcanol Geotherm Res 200:245-254, doi:10.1016/j. jvolgeores.2011.01.001

Bonaccorso A, Cannata A, Corsaro RA, Di Grazia G, Gambino S, Greco F, Miraglia L, Pistorio A (2011b) Multidisciplinary investigation on a lava fountain preceding a flank eruption: the 10 May 2008 Etna case. Geochem Geophys Geosyst 12: Q07009, doi:10.1029/2010GC003480

Bonaccorso A, Caltabiano T, Currenti G, Del Negro C, Gambino S, Ganci G, Giammanco S, Greco F, Pistorio A, Salerno G, Spampinato S, Boschi E (2011c) Dynamics of a lava fountain revealed by geophysical, geochemical and thermal satellite measurements: the case of the 10 April 2011 Mt Etna eruption. Geophys Res Lett 38:L24307, doi:10.1029/2011GL049637

Bonvalot S, Diament M, Germinal G (1998) Continuous gravity recording with Scintrex CG-3 M meters: a promising tool for monitoring active zones. Geophys J Int 135:470-494

Branca S, Carbone D, Greco F (2003) Intrusive mechanism of the 2002 NE-Rift eruption at Mt. Etna (Italy) inferred through continuous microgravity data and volcanological evidences. Geophys Res Lett 30(20):2077

Calvari S, Salerno GG, Spampinato L, Gouhier M, La Spina A, Pecora E, Harris AJL, Labazuy P, Biale E, Boschi E (2011) An unloading foam model to constrain Etna's 11-13 January 2011 lava fountaining episode. J Geophys Res 116:B11207, doi:10.1029/2011JB008407

Cannata A, Catania A, Alparone S, Gresta S (2008) Volcanic tremor at Mt. Etna: inferences on magma dynamics during effusive and explosive activity. J Volcanol Geotherm Res 178(1):19-31, doi:10.1016/j.jvolgeores.2007.11.027

Carbone D, Greco F (2007) Review of microgravity observations at Mt. Etna: a powerful tool to monitor and study active volcanoes. Pure Appl Geophys 164:1-22, doi:10.1007/s00024-007-0194-7

Carbone D, Budetta G, Greco F (2003a) Possible mechanisms of magma redistribution under Mt Etna during the 1994-1999 period detected through microgravity measurements. Geophys J Int 153:187-200, doi:10.1046/j. 1365-246X.2003.01901.X

Carbone D, Budetta G, Greco F, Rymer H (2003b) Combined discrete and continuous gravity observations at Mount Etna. J Volcanol Geotherm Res 123:123-135, doi:10.1016/S0377-0273(03)00032-5

Carbone D, Zuccarello L, Saccorotti G, Greco F (2006) Analysis of simultaneous gravity and tremor anomalies observed during the 2002-2003 Etna eruption. Earth Planet Sci Lett 245:616-629, doi:10.1016/j.epsl.2006.03.055

D'Alessandro A, Scarfi L, Scaltrito A, Di Prima S, Rapisarda S (2013) Planning the improvement of a seismic network for monitoring active volcanic areas: the experience on Mt. Etna. Adv Geosci 36:39-47, doi:10.5194/ adgeo-36-39-2013

Del Negro C, Greco F, Napoli R, Nunnari G (2008) Denoising gravity and geomagnetic signals from Etna volcano (Italy) using multivariate methods. Nonlin Processes Geophys 15:735-749, doi:10.5194/ npg-15-735-2008

Del Negro C, Currenti G, Solaro G, Greco F, Pepe A, Napoli R, Pepe S, Casu F, Sansosti $E$ (2013) Capturing the fingerprint of Etna volcano activity in gravity and satellite radar data. Sci Rep 3:3089, doi:10.1038/srep03089

Furuya M, Okubo S, Sun W, Tanaka Y, Oikawa J, Watanabe H, Maekawa T (2003) Spatiotemporal gravity changes at Miyakejima volcano, Japan: caldera collapse, explosive eruptions and magma movement. J Geophys Res 108(B4):2219, doi:10.1029/2002JB001989

Ganci G, Harris AJL, Del Negro C, Guéhenneux Y, Cappello A, Labazuy P, Calvari S, Gouhier M (2012) A year of lava fountaining at Etna: volumes from SEVIRI. Geophys Res Lett 39:L06305, doi:10.1029/2012GL051026

Greco F, Carmisciano C, Del Negro C, Loretti I, Sicali A, Stefanelli P (2008) Seismicinduced accelerations detected by two parallel gravity meters in continuous recording with a high sampling rate at Etna volcano. Ann Geophys 51(1):87-103, doi:10.4401/ag-4441

Greco F, Currenti G, Del Negro C, Napoli R, Budetta G, Fedi M, Boschi E (2010) Spatiotemporal gravity variations to look deep into the southern flank of Etna volcano. J Geophys Res 115:B11411, doi:10.1029/2009JB006835

Greco F, Currenti G, D'Agostino G, Germak A, Napoli R, Pistorio A, Del Negro C (2012) Combining relative and absolute gravity measurements to enhance volcano monitoring. Bull Volcanol 74:1745-1756, doi:10.1007/s00445-012-0630-0

Kazama T, Okubo S (2009) Hydrological modeling of groundwater disturbances to observed gravity: theory and application to Asama volcano, central Japan. J Geophys Res 114:B08402, doi:10.1029/2009JB006391

Pistorio A, Greco F, Currenti G, Napoli R, Sicali A, Del Negro C, Fortuna L (2011) High-precision gravity measurements using absolute and relative gravimeters at Mount Etna (Sicily, Italy). Ann Geophys 54(5):500-509, doi:10.4401/ag-5348

Seigel HO (1995) A guide to high precision land gravimeter surveys, 2nd edn. Scintrex Ltd. Ontario (chapter 5)

Tobyáš V, Mrlina J, Chán B (1999) Amplitude response of a LCR gravimeter with feedback at periods of microseisms and earthquake waves. Stud Geoph Geod 43(2):185-193, doi:10.1023/A:1023305810018

Williams-Jones G, Rymer H (2002) Detecting volcanic eruption precursors: a new method using gravity and deformation measurements. J Volcanol Geotherm Res 113:379-389

doi:10.1186/1880-5981-66-44

Cite this article as: Greco et al:: Characterization of the response of spring-based relative gravimeters during paroxysmal eruptions at Etna volcano. Earth, Planets and Space 2014 66:44. 